\title{
Application of the Simplest Geophysical Method, the Pricking Probe Method to Map Bedrock Topography in a Karstic Area
}

\author{
S. Szalai* (Hungarian Academy of Sciences), M. Veress (University of \\ West-Hungary), A. Novák (Hungarian Academy of Sciences) \& L. Szarka \\ (Hungarian Academy of Sciences)
}

\section{SUMMARY}

Formation of surface depressions is a significant geological hazard. Prediction of future sinkholes in buried karstic areas needs knowledge about the subsurface. In order to determine the varying topography of the karstifiable bedrock we carried out multielectrode measurements. Due to the hard field conditions, the bedrock depth could not be detected. The resistivity anomalies in some places had a seasonal variation (low-resistivity in springtime, high-resistivity in the end of summer); therefore we interpreted the springtime resistivity lows as indicators of locations with high water content, that is as high porosity, saturated with water. At the same time, when pushing the current- and potential electrodes into the ground, we discovered a regularity in the areal distribution of the soil's rock debris content. Therefore we carried out a systematic electrode-pricking experiment, and categorized the soil's "toughness" corresponding to soft penetration, scratching or blockage within the upper $30 \mathrm{~cm}$. We have found a close relationship between the locations of resistivity- and the soil's toughness extremes. From some epikarstic features we think that high "pricking probe" values indicate smaller depths of the bedrock. The corresponding (springtime) resistivity minima may indirectly indicate more or less collapsed horsts of the carbonate rock. 


\section{INTRODUCTION AND DESCRIPTION OF THE AREA}

The original object of our investigation was reveal the morphology of the buried karstic surface, in order to study the relationship between the surface of the karstifiable rock and its surface signs. If we found such a relationship, it would be possible to make prediction for future buried karstic phenomena on the surface.

The investigated area is situated in the Hárskút basin (Bakony Mts, Hungary), at an altitude of 400-500 m, on a ridge between two walleyes. The surface slightly inclines from $\mathrm{N}$ to $\mathrm{S}$. The original karstic rock is Eocene limestone, which outcrops in several karstic deepenings. The deepenings seem to be clustered in two groups ( $\mathrm{N}$ and $\mathrm{S}$ ), along three lines (NNE-SSW, NW-SE, NNW-SSE). At some junctions the deepenings seem to be accumulated. In both groups ( $\mathrm{N}$ and $\mathrm{S}$ ) a part of former deepenings is filled up with sediments.

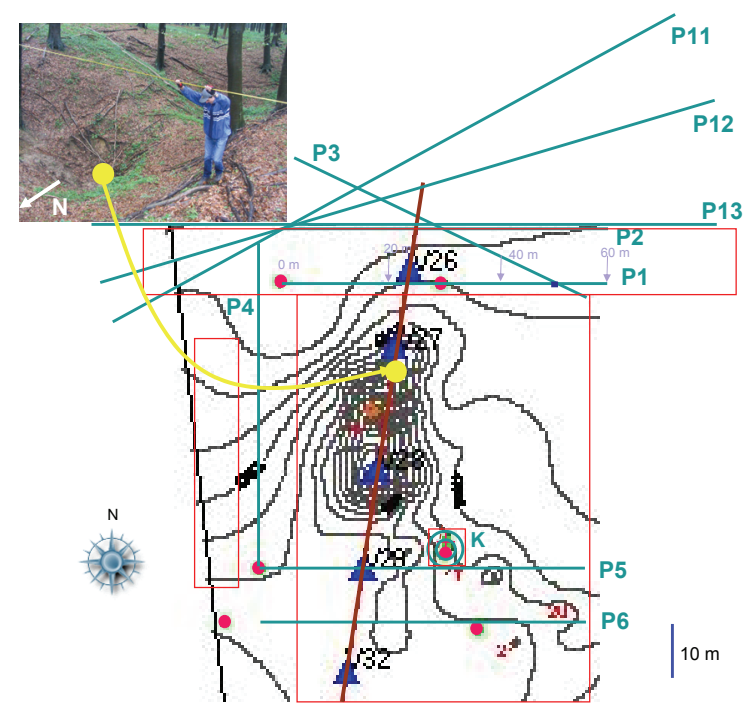

Figure 1: Map of the measuring area with the measuring sites. Geoelectric measurements: profiles P1-P6 and P11-P13; pricking probe: areas bounded by rectangles.

\section{METHODS}

\section{Geoelectric method}

Geophysical measurements were carried out to the North and South of deepening Ho- 8 . In this area (along the profiles, shown in Figure 1) we carried out multielectrode measurements, by using the well-known Wenner and dipole-dipole configurations. The equidistance between the electrodes were $1 \mathrm{~m}$ and $2 \mathrm{~m}$, reaching depth of investigation of about $6.6 \mathrm{~m}, 13.2 \mathrm{~m}$ (with the Wenner array) and $8.7 \mathrm{~m}, 17.6 \mathrm{~m}$ (with dipole-dipole arrays). These values proved to be insufficient to determine the morphology of the karstifiable rock. Longer layouts unfortunately could not be applied, because of the insufficient length of our cables. (Results will be shown later.)

We realised that the electrodes in some places penetrate into the soil more gently than in other sites. Since the distribution of these sites seemed to be systematic, we decided to carry out a very simple ,pricking probe” experiment.

\section{The pricking probe method}

A metal rode with a sharp peak (a usual geoelectric electrode, as shown in Figure 2) is inserted into the subsurface to a given $(30 \mathrm{~cm})$ depth. The rode may penetrate into the soil gently, it may scratch or even stick in. In the first case we assign to the location of the pricking probe a "soil toughness" or superficial "scree distribution" value of $k=0$, in the second one $k=0.5$, in the third case $k=1$. The pricking probe can be carried out either along profiles or over an area. 


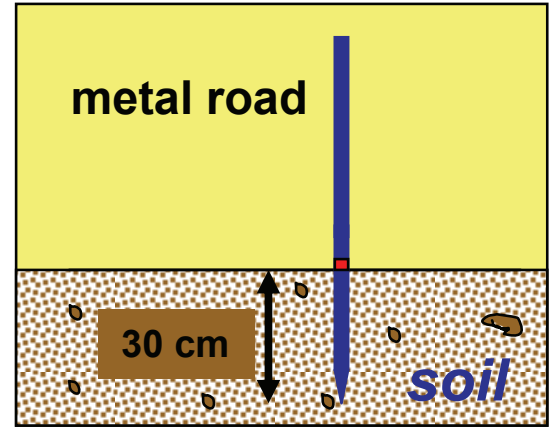

Figure 2: The pricking probe technique.

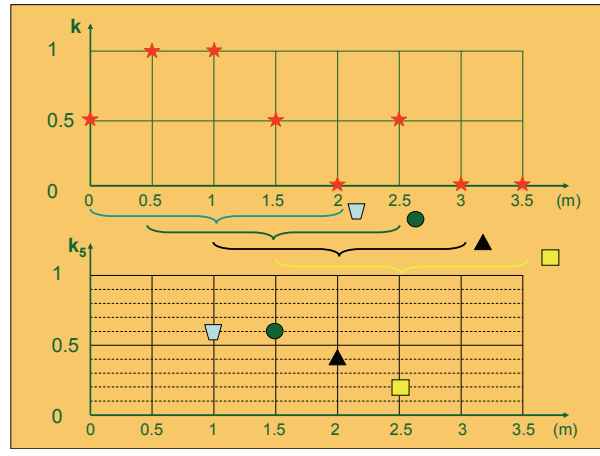

Figure 3: From the individual pricking probe data the moving average $k_{5}$ is computed. (The scree distribution is approximated by $\mathrm{k}_{5}$ ).

Such a characterization is sensitive of course to very local random features (e.g., roots), but a suitable running average of the $k$ value has been proven to be effective to reduce the random features. We applied $30 \mathrm{~cm}$ as penetration depth and $50 \mathrm{~cm}$ as equidistance between the neighbouring pricking-probe sites and 5 as running average. In Figure 3 the effect of running average $k_{5}$ is illustrated. Results of two consecutive measurements along the same profile justified the qualitative repeatibility of the pricking probe measurement. Results along two parallel profiles (quasi perpendicular to the assumed direction of the underground structure), at a distance of $5 \mathrm{~m}$ of each other showed a large similarity, too.

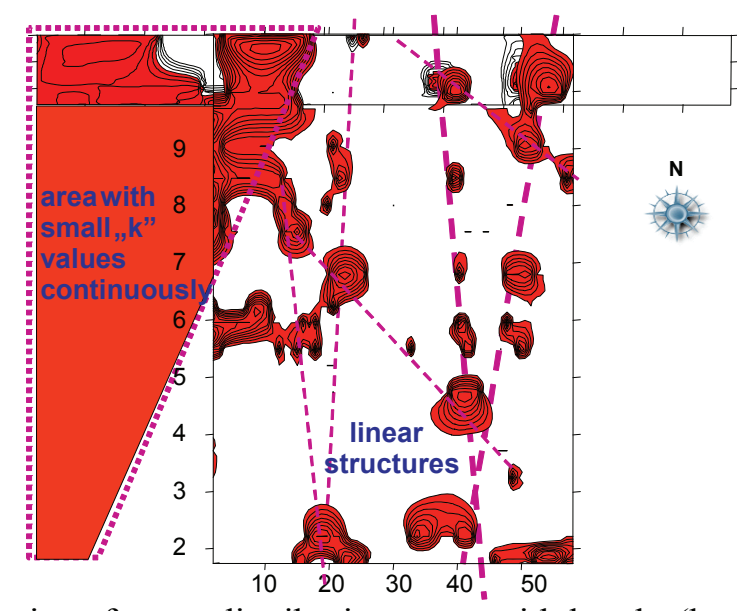

Figure 4: Domains of scree-distribution maps with low $\mathrm{k}_{5}\left(\mathrm{k}_{5}<0.2\right)$ values.

We have found regularity when considering sites with $k_{5}$ values lower than 0.2 (Figure 4). In the Western part of the area the soil is everywhere soft, while in the Eastern part such small $k_{5}$ values were observed only in several sites. These sites are aligned, referring to the regularity of the areal distribution of the soil's rock debris content. The sites having $k_{5}$ values larger than 0.5 also have regularity (Figure 7).

The question is as follows: what information is hidden in the debris distribution?

\section{COMPARISON BETWEEN GEOELECTRICS AND PRICKING PROBE}

A detailed comparison between the geoelectric resistivity values and the pricking probe test measurements was carried out around a nearly perfectly circular karstic sink, shown in Figure 5. The sink was surrounded circularly with equidistant electrodes. The standard apparent resistivity and the $k_{5}$ values were plotted in form of polar diagrams (Figure 6). Both the resistivity polar diagram and the $k_{5}$ polar diagram indicate the same two main characteristic directions. As Figure 6 shows, low $k_{5}$ values accompany with high electrical resistivity values and vice versa. A similarly good correlation was observed in areal measurements, too. Just an 
experience: at a depth of $3.5 \mathrm{~m}$ the average apparent resistivity along profile 3 was about 200 ohmm, along profile 4 it was about $600 \mathrm{ohmm}$. As it seen in Figure 7, profile 4 is in a low $k_{5}$ zone, while along profile 3 the scree distribution is higher. For this regularity we have set up a possible physical model, which will be discussed later.

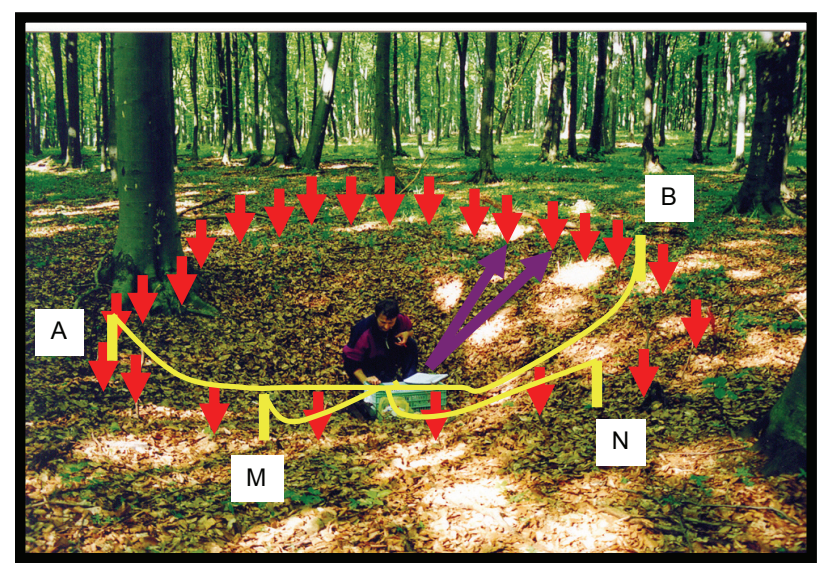

Figure 5: The circular depression with the current $(\mathrm{A}, \mathrm{B})$ and potential $(\mathrm{M}, \mathrm{N})$ electrodes.

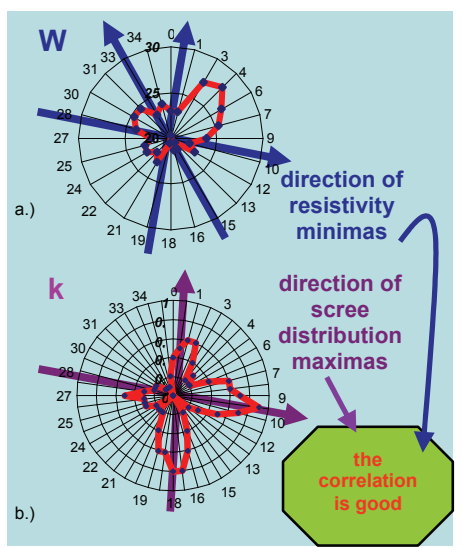

Figure 6: Resistivity and pricking probe polar diagrams. a.) apparent resistivity polar diagram;b.) pricking probe polar diagram.

\section{PHYSICAL MODELS}

A physical model for the regularity of $\boldsymbol{k}_{5}$ : The physical model is still under discussion, but we assume that the sediment cover corroded to the present level, thus the present (horizontal) surface is in the former epikarstic zone. Where the present surface is farther from the original surface of the karstifiable rock, the weathering should be more advanced.

A physical model for the resistivity anomalies: Resistivity variation must be either due to the variation in the rock quality or, alternatively, due to the variation of the water content. The interpreted anomaly in the near-surface region reminds to water infiltration, and they might be inter-connected at depth (Figure 8). Therefore we think, the conductivity anomalies are rather due to changes in water content than due to rock quality changes. Figure 8 , where interpreted results of springtime and end-of-summer measurements are shown together, provides a real clincher. In zones I and II the resistivity increase from spring to late summer must indicate a significant decrease in humidity. Conclusion: The low resistivities (at least in springtime) indicate high porosity locations saturated with water.

\section{Implication from the physical model:}

a) resistivity and $k_{5}$ are in a reciprocial relationship

b) $k_{5}$ and the depth of the basement are in a reciprocial relationship

c) (springtime) resistivity and high porosity are in a reciprocial relationship

It follows from a-b-c that there must be also a reciprocial relationship between the depth of the basement and the porosity of the cover. Namely, the porosity is the highest where the depth to the karstifiable rock is the smallest, and vice versa. From this assumption it follows that the most exposed sites to karstification (hole formation) are the horsts of the basement.

\section{CONCLUSIONS}

In an area, characterised by a group of dolines, we investigated the pattern of the limestone surface. The results are twofold:

1. We have developed an extremely simple, but effective mechanical method. From the scree distribution in the uppermost near-surface region it is possible to infer to the morphological variation of the limestone floor. The results of the near-surface screedistribution, obtained by the so-called pricking probe method have been found to be in a good correlation with the results of a classical multielectrode geophysical method. 
2. By a joint application of geolectric and pricking probe techniques, we have been able to construct a reasonable physical model for the karstification process. Namely, the multielectrode DC geoelectric method allows providing the electric resistivity distribution beneath a given profile. The areal distribution of scree at the surface, determined by the picking probe method, refers to the morphology of the limestone surface.

We have identified the low resistivity sections in the resistivity profiles as locations, where the water content is high in the sediment cover. This implies high local porosity. At the same time, the scree-distribution maxima must be due to the higher position of the limestone floor. On basis of the two aforementioned conclusions, we established a direct relationship between the basement depth and the scree-distribution. Namely, a higher position of the limestone floor has been found to be accompanied with higher porosity of the sediment. (With other words: the sediment cover above a limestone surface has higher porosity, where it is thinner.) We propose a geological justification of this conclusion: a caverning process in the limestone body results in a slackening in the sediment, thus the more porous sections in the sediment cover appear as a consequence of the karstification of the limestone.

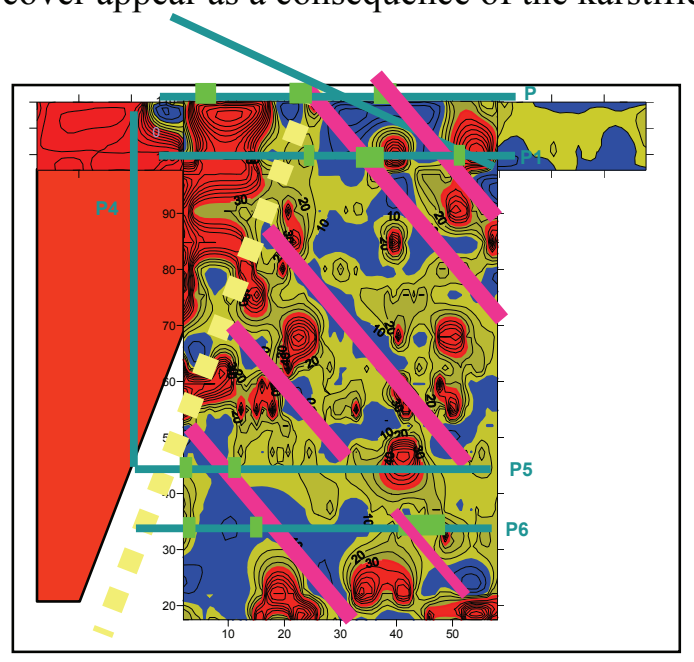

Figure 7: Scree-distribution map (red: $\mathrm{k}_{5}<0.2$ ) (green: $0.2<\mathrm{k}_{5}<0.5$, blue: $\mathrm{k}_{5}>0.5$ ). Low-resistivity zones (marked with thick stripes along the resistivity profiles) and high scree-distribution zones (marked with long, nearly NW-SE directed thick lines) are also shown.

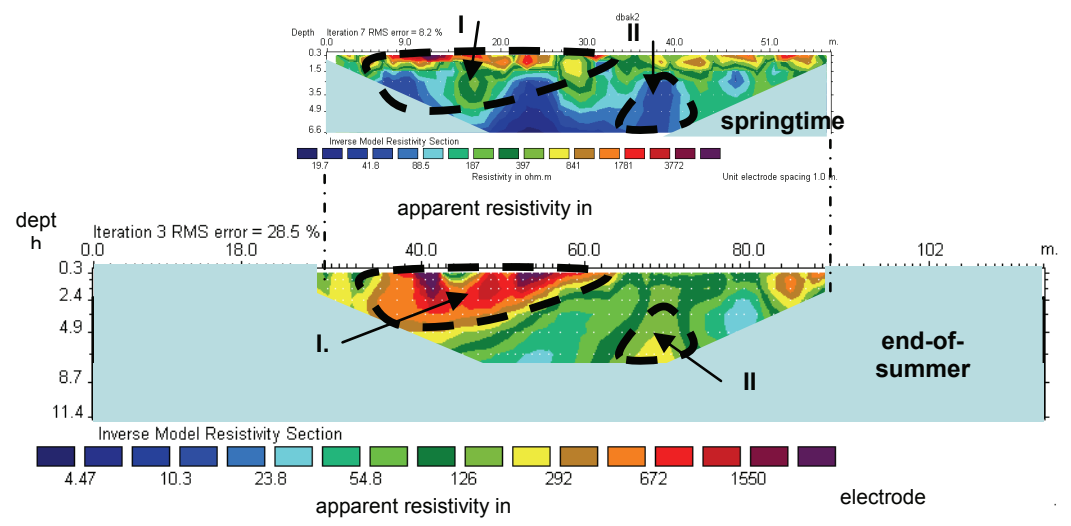

Figure 8: The interpreted Wenner resistivity pseudo-section along the same profile (P2) from two different measurements. a) spring-time, b) end of summer.

\section{ACKNOWLEDGMENTS}

Hungarian Scientific Research Fund (projects T049604 and NI 61013). Sándor Szalai is a grantee of the Bolyai János Scholarship of the Hungarian Academy of Sciences. 